\title{
Pepper root rot resistance and pepper yield are enhanced through biological agent G15 soil amelioration
}

\author{
Xuejiang Zhang ${ }^{1,2,3}$, Dazhao Yu ${ }^{\text {Corresp., 1, 2, } 3}$, Hua Wang ${ }^{\text {Corresp. 1, 2, } 3}$ \\ ${ }^{1}$ Institute of Plant Protection and Soil \& Fertilizer, Hubei Academy of Agricultural Sciences, Wuhan, Hubei Provience, China \\ 2 Hubei Key Laboratory of Crop Disease, Insect Pests and Weeds Control, Wuhan, Hubei Province, P. R. China \\ ${ }^{3}$ Key Laboratory of Integrated Pest Management on Crops in Central China, Ministry of Agriculture, Wuhan, Hubei Province, P. R. China \\ Corresponding Authors: Dazhao Yu, Hua Wang \\ Email address: dazhaoyu1956@126.com,wanghua4@163.com
}

Pepper root rot is a serious soil-borne disease that hinders pepper production, and efforts are being made to identify biological agents that can prevent and control pepper root rot. Our group recently discovered and produced a biological agent, named G15, which reduces the diversity and richness of fungi and bacteria when applied to pepper fields. In the soil of the G15-treatment condition, the pathogenic fungus Fusarium was inhibited, while the richness of beneficial bacteria Rhodanobacter was increased. Also, the ammonia nitrogen level was decreased in the G15-treatment soil, and the $\mathrm{pH}$, total carbon, and total potassium levels were increased. Compared to the control condition, pepper yield was increased in the treatment group (by $16,680 \mathrm{~kg}$ acre-1). We found that G15 could alter the microbial community structure of the pepper rhizosphere. These changes alter the physical and chemical properties of the soil and, ultimately, improve resistance to pepper root rot and increase pepper yield. 


\section{Pepper Root Rot Resistance and Pepper Yield are Enhanced 2 Through Biological Agent G15 Soil Amelioration}

4 Xuejiang Zhang ${ }^{1,2,3}$, Dazhao $\mathrm{Yu}^{1,2,3}$, Hua Wang ${ }^{1,2,3}$

$6{ }^{1}$ Institute of Plant Protection and Soil \& Fertilizer, Hubei Academy of Agricultural Sciences, 7 Wuhan, Hubei Province, P. R. China.

$8{ }^{2}$ Key Laboratory of Integrated Pest Management on Crops in Central China, Ministry of 9 Agriculture. P. R. China, Wuhan, Hubei Province, P. R. China.

$10{ }^{3}$ Hubei Key Laboratory of Crop Disease, Insect Pests and Weeds Control, Wuhan, Hubei 11 Province, P. R. China.

14 Corresponding Authors:

15 Hua Wang ${ }^{1,2,3}$

16 Email address: wanghua4@163.com

Dazhao $\mathrm{Yu}^{1,2,3}$

Email address: dazhaoyu195611@ssina.com 


\section{Abstract}

32

Pepper root rot is a serious soil-borne disease that hinders pepper production, and efforts are being made to identify biological agents that can prevent and control pepper root rot. Our group recently discovered and produced a biological agent, named G15, which reduces the diversity and richness of fungi and bacteria when applied to pepper fields. In the soil of the G15-treatment condition, the pathogenic fungus Fusarium was inhibited, while the richness of beneficial bacteria Rhodanobacter was increased. Also, the ammonia nitrogen level was decreased in the G15-treatment soil, and the $\mathrm{pH}$, total carbon, and total potassium levels were increased. Compared to the control condition, pepper yield was increased in the treatment group (by 16,680 $\left.\mathrm{kg} \mathrm{acre}{ }^{-1}\right)$. We found that G15 could alter the microbial community structure of the pepper rhizosphere. These changes alter the physical and chemical properties of the soil and, ultimately, improve resistance to pepper root rot and increase pepper yield.

\section{Introduction}

Pepper (Capsicum annum L.) root rot is a serious soil-borne disease caused mainly by Fusarium sp. and Phytophthora capsici Leon (Aboelnaga et al., 2007; Pérez-Hernández et al., 2014). The Hymenophora subfamily is responsible for pepper root rot, and the family members include $F$. solani, F. vasinfectum Atk., F. equiseti (Corda) Sacc., F. moniliforme, F. oxysporum Schlecht., and F. verticillioide (Jaber and Alananbeh 2018). The pathogen invades the plant vascular bundle from the micro-wounds on the roots and stems of the pepper, causing mycelium, sclerotia, and chlamydospores to overwinter in the plant residues and field soil. The chlamydospores of the pathogen are highly resistant to stress, and they generally live in the soil for 3 to 4 years and even up to 10 years (Beckman, 1987). These conidia are spread by irrigation (e.g., water, rainwater, and dew). The development of intensive cultivation and facility cultivation technologies, the use of long-term continuous cropping and simple rotation in vegetable fields has led to the continuous decline of soil quality, where the number of beneficial 
57 microorganisms in the soil has plummeted alongside the accumulation of pathogens (Hussain et 58 al., 2009). Therefore, peppers grown in this soil are more prone to root rot (Ma et al. 2008; Ikeda 59 et al., 2010; Coolon et al., 2013; 2013; Cao et al. 2014; Sun et al., 2015).

60 The control methods of pepper root rot mainly include agricultural control (reasonable 61 rotation, especially film-covered high-ridge cultivation, and seed disinfection), chemical control 62 (40\% fluosilazole emulsifiable concentrate, 25\% propiconazole emulsifiable concentrate, 3\% 63 Guangkuling $+70 \%$ metoprolol, dibenzofuran, and diisooctyl phthalate), biological control 64 (Bacillus amylolique Faciens (Ohkuma et al., 2001; Chen et al., 2007), B. subtilis wettability 65 66 Powder (Jayaraj et al., 2005), and breeding and screening for disease-resistant varieties. The biological control of crop root rot is mainly Trichoderma, such as T. harzianum, T. viride, T. hamatum, and T. longibrachiatum, T. polysporum and T. asperellum, etc. The trichomycin secreted by these fungi is the main substance that inhibits crop root rot. A variety of Bacillus species are also important biocontrol bacteria that inhibit root rot of crops. The antibacterial substances produced by them mainly dissolve cell walls or cell membranes, causing protoplasm leakage to break or deform the hyphae, and inhibit the germination of pathogenic bacteria spores to achieve the effect of inhibiting pathogenic bacteria (Ohkuma et al., 2001). Existing biological agents, such as B. subtilis, B. cereus, and B. amyloliquefaciens, change the composition of the soil microbial community in the rhizosphere (e.g., by increasing bacterial diversity or reducing fungal diversity), and increasing pepper resistance to root rot (Francis et al., 2010; Bhat, 2013; Han et al., 2019). Alternatively, introducing certain biological agents might be effective, to some extent, as bio-fertilizers and, at the same time, offer different mechanisms for controlling plant disease rather than chemical pesticides (Fravel, 2005; Mehta et al., 2014; Luo et al., 2018; Ekea et al., 2019).

Therefore, maintaining a high level of microbial diversity in the soil is essential for the sustainable development of the pepper industry (Kennedy and Smith, 1995; Bhat, 2013). It has been reported that inorganic fertilizers can reduce the diversity and abundance of bacteria (Ramirez et al., 2010; Coolon et al., 2013; Zhou et al., 2015), but the application of organic greater biodiversity in long-term fertilized soils (Ding et al., 2016).

The microbial fertilizer (G15) developed by our laboratory, which uses Bjerkandera sp. as 87 the main microbial source (Wang, 2018 patent number: ZL 20151 0564715.4; Wang, 2020 
88

89

90

91

92

93

94

95

96

97

98

99

100

101

102

103

104

105

106

107

108

109

110

111

112

113

114

115

116

117

patent number: 2020101644), has a good inhibitory effect on a variety of soil-borne bacteria and fungal diseases. The G15 is fermented by Bjerkandera sp., pig manure, straw, soybean meal, urea, etc. in proportion, and is highly safe to crops. From the perspective of plant growth, the plant height, root length, whole plant fresh weight, and root fresh weight of the G15-treatment pepper were significantly different when compared to the control condition (Cai et al., 2019). Therefore, the current study aims at assessing the microbial variation of the pepper rhizosphere, evaluating the effects of G15 on controlling the pepper root rot disease and, at the same time, improving the nutritional status of the grown plants, thus maintaining pepper field sustainability.

\section{Materials \& Methods}

\section{Site description and experiment layout}

Field experiments were approved by the Research Council of the Institute of Plant Protection and Soil \& Fertilizer, Hubei Academy of Agricultural Sciences (project number: 18.010.15).

The Institute of Plant Protection and Soil \& Fertilizer, Hubei Academy of Agricultural Sciences granted Ethical approval to carry out the study within its facilities (Ethical Application Ref: hb35 8-a7c6d).

The field experiment was located in Xinhua town of Shennongjia Forest, Hubei province, China $\left(31^{\circ} 59^{\prime} \mathrm{N}, 110^{\circ} 89^{\prime} \mathrm{E}\right)$. This region has a subtropical monsoon climate, with an average annual temperature of $12^{\circ} \mathrm{C}$ and $1170.2 \mathrm{~mm}$ of precipitation. The land belongs to flat terrain and uniform soil quality. The soil in this field was characterized as mountain dark brown soil with a $\mathrm{pH}$ of 5.35 (10:1 water to soil ratio), and it contains $0.783 \mathrm{~g} \mathrm{~kg}^{-1}$ total $\mathrm{N}, 4.51 \mathrm{~g} \mathrm{~kg}^{-1}$ total P, and $46.31 \mathrm{~g} \mathrm{~kg}^{-1}$ total $\mathrm{K}$ (Liang et al., 2011). The field experiment was performed in a completely randomized block design with three replicates for each of the two treatments: G15 treatment and the control condition. which can ensure that the initial conditions of $\mathrm{C}$ and $\mathrm{G}$ are exactly the same. The cultivation and management methods of the control and treatment are the same, except that G15 microbial fertilizer is not added. G15 is a kind of microbial fertilizer, pig manure, straw, corn stover, sugar, urea, and water, which are necessary as its substrate. This is also the biggest difference between microbial fertilizer and microbial inoculants. The area of each repeat is $300 \mathrm{~m}^{2}$. There are 1000 peppers in $300 \mathrm{~m}^{2}$. Ridge forming first, $0.8 \mathrm{~m}$ ridge distance, the powdery G15 microbial fertilizer was applied to the middle of the ridge distance at one time. The 
118 ridge forming conditions of the control were consistent with G15 treatment. The tested pepper 119 variety is "Xiangshuai". The bred pepper seedlings were planted on May 21, 2019, with plant 120 spacing $0.4 \mathrm{~m}$. Cultivation and water management are carried out according to conventional 121 cultivation management mode.

122

Field pepper biological character and disease index survey

124 When the pepper is grown about two months, that is, in mid-July, the physiological 125 characteristics of the plant, including the plant height, root length, root fresh weight, and root dry 126 weight were measured. These indicators can reflect the growth-promoting effect of G15 microbial fertilizer on pepper. The stronger the plant, the stronger the resistance to root rot. We also recorded the incidence of root rot disease and tested whether G15 treatment reduced pepper root rot. Chinese peppers are harvested in five to six batches during the picking period. After the third batch, pepper root rot disease has obvious symptoms. Therefore, collecting pepper rhizosphere soil samples at this time can more truly reflect the changes in soil microorganisms. So as to better explain the mechanism of G15 microbial fertilizer to prevent and control pepper root rot. Picking peppers began around July 25, and picking a batch of peppers every 10 to 12 days, a total of 5 batches were picked. Regarding the harvesting statistics of peppers, the comparison can only be made after selecting three batches. Five batches of peppers treated with G15 were picked. The height of the pepper plant is measured with a meter ruler, and the root length is measured with a centimeter ruler. Both have one decimal place, but when the average value is reached, two decimal places are kept. After all batches were picked, the total production statistics were calculated.

The disease is classified according to the ratio (\%) of the diseased root system to the total root system: grade 0, no disease; grade 1, the root system is slightly discolored, and the

142 discolored root system accounts for less than $10 \%$ of the total root system, and the plant does not 143 wilt; grade 3, the root system is obviously browned, the discolored root system accounts for 10$14430 \%$ of the total root system, and the plant begins to wilt; at level 5, the discolored root system 145 accounts for $30 \%$ to $50 \%$ of the total root system, and the plant is obviously wilting; at level 7 , 146 the discolored root system accounts for $50 \%$ to $80 \%$ of the total root system, plants are wilting; 147 level 9, the whole plant is dead (Sun et al. 2018). Sixty plants was measured in each plot, 148 including healthy and diseased plants. 
150

151

152

153

154

155

156

157

158

159

160

161

162

163

164

165

166

167

168

169

170

171

172

173

174

175

176

177

178

179

\section{Soil sampling and properties analysis}

The focus of research was the role of G15-treatment in the prevention and control of pepper root rot when root rot disease occurred in pepper. The only difference between the control and the treatment was whether or not G15 microbial fertilizer was added, so this experiment did not take the soil sample before treatment

Soil sampling was performed between the second and third picks of peppers. Due to ground flatness, uneven water and fertilizer, the soil of the same plot will have differences in the microbial community structure. In order to reduce the impact of these differences on the analysis of the sample community structure, a five-point sampling method will be used in the set plot perform sample mixing. Each treatment took 5 points and mixed them into one sample. There were three replicates in the same treatment group, and a total of three samples were taken.

It is to study the microbiome in environmental samples, so the DNA of the entire soil sample must be extracted. In addition to the soil, the rhizosphere soil samples will also contain some litter and plant roots. If they are not screened, the DNA information of these litters and plant roots will also be extracted together, which will affect the effective data of sequencing. This kind of operation is to reduce the deviation and will be used in many documents. The bulk soil separated from the root was air-dried for the determination of physicochemical properties $\left[\mathrm{pH}\right.$, total organic carbon (TOC), $\mathrm{NH}^{+}-\mathrm{N}$, total $\mathrm{N}(\mathrm{TN})$, total P (TP), total K (TK)] following the methods described in Shen et al. (2013).

\section{DNA extraction, PCR amplification, library preparation, and Miseq sequencing}

Microbial DNA was extracted from six samples using the E.Z.N.A.® soil DNA Kit (Omega BioTek, Norcross, GA, US) according to the manufacturer's protocols. The final DNA concentration and purity were determined using a NanoDrop 2000 UV-vis spectrophotometer (Thermo Scientific, Wilmington, USA), and the DNA quality was checked by $1 \%$ agarose gel electrophoresis. DNA extracted from each soil sample served as a template for the amplification of the 16S rRNA gene and the internal transcribed spacer region. Bacterial primers 338F (5'ACT CCT ACG GGA GGC AGC AG-3') and 806R (5'-GGA CTA CHV GGG TWT CTA AT3') were used to amplify the V3-V4 hypervariable regions of the bacterial 16S rRNA gene, while the ITS1 region of the fungal ITS was targeted by ITS1F (5'-CTT GGT CAT TTA GAG GAA 
180

181

182

183

184

185

186

187

188

189

190

191

192

193

194

195

196

197

198

199

200

201

202

203

204

205

206

207

208

209

GTA A-3') and ITS4 (5'-GCT GCG TTC TTC ATC GAT GC-3'). When doing amplicon sequencing, it is generally not technically repeated on DNA samples, but on PCR products. After the DNA is extracted in this experiment, 3 PCR repeats will be performed on each sample, and the PCR products of these 3 repeats will be mixed for subsequent library construction and sequencing. The resulting PCR products about 300 base pair were extracted from a $2 \%$ agarose gel and further purified using the AxyPrep DNA Gel Extraction Kit (Axygen Biosciences, Union City, CA, USA) and quantified using QuantiFluor-ST (Promega, USA) according to the manufacturer's protocols. Purified amplicons were pooled in equimolar and paired-end sequenced $(2 \times 300)$ on an Illumina MiSeq platform (Illumina, San Diego, US) according to the standard protocols by Majorbio Bio-Pharm Technology Co. Ltd. (Shanghai, China). The raw reads were deposited into the NCBI Sequence Read Archive (SRA) database (Accession Number: SRP265722)

\section{Sequence data processing}

Raw FastQ files were demultiplexed, quality-filtered by Trimmomatic, and merged by FLASH using the following criteria: (i) The reads were truncated at any site receiving an average quality score $<20$ over a 50 bp sliding window; (ii) Primers were exactly matched, allowing two nucleotide mismatching, and reads containing ambiguous bases were removed; (iii) Sequences with an overlap of longer than $10 \mathrm{bp}$ were merged according to their overlap sequence. Operational taxonomic units (OTUs) were clustered with 97\% similarity cutoff using UPARSE (version $7.1 \mathrm{http}: / /$ drive5.com/uparse/), and chimeric sequences were identified and removed using UCHIME. The taxonomy of each 16S rRNA gene sequence was analyzed by the RDP Classifier algorithm (http://rdp.cme.msu.edu/) against the Silva (SSU123) 16S rRNA database using a confidence threshold of $70 \%$.

\section{Statistical analysis}

An OTU-based analysis was performed to detect the microbial community richness and diversity between biological agent treatment and control. Richness was estimated using the Chao index, while the Shannon diversity index was calculated to estimate the number of observed OTUs that were present. 
210 All statistical tests performed in this study were considered statistically significant at $P<$ 2110.05 . The data were tested for normality and transformed when necessary to meet the criteria for 212 a normal distribution. Duncan and pairwise comparison tests were used to assess the effect of 213 G15 treatment on pepper yield and microbial community, respectively. Multiple analysis of 214 variance (MANOVA) using the SigmaPlot software program was used to determine the effects 215 of G15 (relative to the control condition) on the dependent variables, soil characteristics, relative 216 abundances of abundant taxa, and $\alpha$-diversity indices, including the Chao and Shannon indices.

217 Differences in microbial community composition when comparing the G15-treatment and 218 control conditions were tested by ANOSIM. Non-metric multidimensional scaling (NMDS) 219 based on the Bray-Curtis distance was performed to illustrate the B-diversity for bacteria and 220 fungi.

221

222

\section{Results}

223

224

225

226

227 228

229

230

231

232

233

234

235

236

237

238

239

\section{Impacts of G15-treatment on pepper root rot, biological characteristics, pepper yield}

G15 application significantly (Duncan test, $P<0.05$ ) increased plant height (by $17.87 \mathrm{~cm}$ ), root length (by $9.56 \mathrm{~cm}$ ), root fresh weight (by $9.56 \mathrm{~g}$ ), root dry weight (by $2.13 \mathrm{~g}$ ), and pepper yield (by 16,680 kg acre-1) (Table 1). By enhancing the growth of pepper plants, the plants themselves are strong. Compared with the control treatment, the $\mathrm{G}$ amendment has a disease index of only 3.22 , and the control effect reached $77.5 \%$.

\section{Impacts of G15-treatment on soil physicochemical characteristics}

Supplementing the soil with G15 generally resulted in significantly higher soil $\mathrm{pH}$, TOC, and TK, but the concentrations of $\mathrm{NH}_{4}{ }^{+}-\mathrm{N}$ decreased significantly relative to the control condition (Table 2). No significant differences in soil TN and TP were detected when comparing the G and $\mathrm{C}$ conditions, and their interaction terms were also not significant.

\section{Impacts of G15-treatment on microbial community a-diversity}

We detected big variation in the estimated richness and diversity indices when comparing the bacterial and fungal communities of the G15 and C soils (Table 3). From the Sobs and Chao indices (reflecting the community richness) and the Shannon and Simpson indices (reflecting the 
240 community diversity), the G15 supplemented soil had a significantly lower richness and diversity

241 for bacteria and fungi relative to the control condition.

242

243

\section{Impacts on microbial community structure}

244 Sample hierarchical clustering analysis and non-metric multidimensional scaling (NMDS) were 245 performed in each community for fungi and bacteria, respectively (Figure 1). Actually, the 246 clustering effect by treatment was the same in the fungi and bacteria analysis.

A heatmap analysis of the genera-level community richness of fungi and bacteria (top 50)

248 found that only two-fifths of the fungal genera had a richness greater than 1, and the community 249 structure was relatively simple. Three-quarters of the genera of bacteria had an richness of more 250 than 1, and the community structure was more complicated (Figure 2).

251

\section{2}

\section{Impacts of G15-treatment on microbial community taxonomic composition}

254 fungal phyla.

For the fungal population, there were 39 genera in the two treatments-conditions and 22 256 endemic genera in control, and there was a special Pezizales in the G15-treatment. The fungi were mostly rotted on humus-rich soil, plant residues, or manure. For the bacterial population, there were 245 genera in total in the two treatments, 120 endemic genera in the control condition, and only 47 endemic genera in the G15- treatment (Figure 3).

Fungal diversity analysis found that the proportion of Phialemonium in the G15 treatment group was significantly higher than that of the control group, while the proportion of Fusarium that is responsible for pepper root rot - was significantly lower than that of the control group. Bacterial diversity analysis found that the proportion of Rhodanobacter in the G15 treatment group was much higher than in the control group (Figure 4).

\section{Discussion}

In vegetable fields with long-term application of chemical fertilizers, the soil acidity is generally 
270 plants that are susceptible to root rot disease, resulting in extremely low pepper production (Ekea 271 et al., 2019). The G15 microbial fertilizer greatly changed the physical and chemical properties 272 of pepper rhizosphere soil. The $\mathrm{pH}$ value of G15 microbial fertilizer is about 8.4. After several 273 months of growth of pepper, the microbial fertilizer interacts with the soil and the pepper roots, 274 and the $\mathrm{pH}$ value of the rhizosphere soil reaches about 7.5. Compared to G15 treatment, the $\mathrm{pH}$ 275 value of the control group is around 5.5. The increase in the $\mathrm{pH}$ following the application of G15 276 also contributes to the growth inhibition of pathogenic bacteria and likely has a preventive effect 277 (Cai et al., 2019).

278 At the same time, we also found that in G15 treatment, the K content of rhizosphere soil 279 was significantly higher than that of the control group. Some studies think the soluble forms of $\mathrm{K}$ 280 are good for plant growth and yield (Singh et al., 2014). The treatment group can accumulate 281 more $\mathrm{K}$ ions and more carbon, which is also important for enhancing the nutrient absorption of 282 pepper and resistance to pepper root rot. After applying G15 to the pepper field, we found that 283 the root system of the G15 treated plants was more developed, which helps to resist the invasion 284 of root rot fungi; the stem was thicker and can resist lodging, which is beneficial to nutrient 285 absorption; the leaves were more green, which presumably benefited photosynthesis. We found 286 that the G15 treated plants had a longer flowering time than that the control plants, and the fruitbearing period was about one month longer in the G15 treated plants than that in the control plants. Pepper production was increased by $16,680 \mathrm{~kg} \mathrm{acre}^{-1}$ in the G15-treatment condition 289 relative to the control condition.

The main function of G15 microbial fertilizer is to prevent and suppress diseases, while 291 promoting plant growth and increasing crop yield. Even if G15 microbial fertilizer is applied, 292 some root rot diseases of peppers are normal. Because the disease prevention efficiency reaches more than $70 \%$, it shows that the effect of this microbial fertilizer is very efficient. To explore the disease-resistance mechanism of G15, we studied the microbial diversity and community 295 structure of the pepper rhizosphere. We found that the fungal and bacterial diversity and community richness of the G15 treated soils were lower than those of the control condition, which is somewhat different from the findings of a previous study (Qiao et al., 2019). In the G15-treatment condition, the fungal and bacterial community structures were relatively simpler, but the richness of the genera was higher than those in the control condition. This might be 
301 applied by stripping rather than spreading. The strip application method concentrates the G15 in

302 the ridge area where the pepper is planted, which greatly changes the micro-environment around 303 the root of the pepper. A unique Pezizales was found from the G15 treatment in the fungal 304 community, which was more abundant. The Pezizales were mostly rotted on humus-rich soil, 305 plant residues, or manure. This is also the result of the fungal effect by concentrating on the root 306 of the pepper.

307 The difference between microbial fertilizers and microbial inoculants is that the 308 microorganisms can be compounded in the corresponding matrix to better function. However, 309 because there is no matrix, the microbial inoculants are directly applied to the field, and their 310 effects will be affected by many factors, resulting in great effectiveness reduce. In the past 311 experiments of applying organic fertilizer, it can also increase production, and the microbes in 312 the rhizosphere of crops will also change, but the changes of these microbes cannot interact with 313 the root rot of the crops, thereby preventing and controlling crop root rot (Tao et al., 2020). 314 Therefore, the difference in microbial changes in the rhizosphere of pepper caused by the 315 application of Gao's No. 15 microbial fertilizer in this study is the main reason for inhibiting 316 pepper root rot.

317 The pepper root rot-causing Fusarium genus is much more abundant in the control group 318 than in the G15 treatment group. We propose that after the application of G15, the fungus 319 interacts with pepper roots and the rhizosphere soil. The fungus inhibits the growth of some other 320 fungi and bacteria in the soil, resulting in the reduced fungal abundance, diversity, and richness 321 in the treatment group. The fungus itself has a strong inhibitory effect on Fusarium, resulting in 322 an extremely low abundance of Fusarium in the treatment group.

At the same time, the application of G15 increased the richness of some beneficial bacteria 324 (e.g., the richness of Rhodanobacter sp was much higher in the G15-treatment condition than in 325 the control condition). Rhodanobacter sp is a denitrifying bacterium that can efficiently degrade 326 ammonia nitrogen in the soil (Prakash et al., 2012; Green et al., 2012; Hemmc et al., 2016). 327 However, there is relatively few research on its biological control effect. Dománski (1982) 328 isolated from the bark of American red oak and scutellaria, a strain of Fumaria tuberculosis that 329 inhibits Glycophyllum vulgaris, effectively preventing brown rot from occurring on oak trees. 330 Bak et al. (2011) isolated a strain of biocontrol fumigatus in a planting area contaminated by 331 pathogenic bacteria in Korea. The results of the study showed that fumigatus could grow on PDA 
332 medium at $5^{\circ} \mathrm{C} \sim 35^{\circ} \mathrm{C}$, and the bacteria could also significantly inhibit the pathogen Lentinula 333 edoes, effectively prevent the occurrence of dry rot on black poplar in Europe and America. 334 Wang et al. (2015) disclosed that tobacco tube fungus has a good inhibitory effect on root rot, 335 verticillium wilt, bacterial wilt, etc., and found that the granules prepared with this strain can 336 significantly control tomato bacterial wilt, blight, cotton root rot, verticillium wilt, watermelon 337 root rot wilt, etc. Rhodanobacter strains have different denitrification capabilities at the genetic 338 level (Hemmc et al., 2016). In an acidic and nitrate-rich environment, Rhodanobacter strains 339 exhibit high relative abundance and activity, and all have complete denitrification capabilities 340 (Green et al., 2012), indicating that Rhodanobacter strains may maintain their own growth using 341 high concentrations of the nitrates. During the growth process of pepper, if the ridge is not 342 sufficiently high and is waterlogged, pepper root rot is more likely happened. Therefore, in the 343 G15-treatment condition, the extremely rich Rhodanobacter might efficiently degrade excessive 344 ammonia nitrogen in the pepper rhizosphere, thereby reducing the occurrence of pepper root rot . 345 This can also be seen from the soil's physical and chemical indicators. The ammonia nitrogen in 346 the treatment group was only a quarter of that in the control group, indicating that the beneficial 347 bacteria Rhodanobacter $\mathrm{sp}$ in the treatment group plays an important role in degrading excess 348 ammonia nitrogen in the rhizosphere. This might be the key to the G15-mediated inhibition of 349 pepper root rot.

\section{Conclusions}

351 It is notoriously difficult to identify biological agents that contribute to pepper root rot resistance 352 and increase pepper yield. Nevertheless, our group identified the biological agent G15, which 353 improves the richness of the beneficial bacteria Rhodanobacter sp. and decreases the abundance 354 of the pathogenic Fusarium genus. G15 supplementation alters the physical and chemical 355 properties of the soil in a way, especially increasing the $\mathrm{pH}$ value of the soil, and enriching $\mathrm{K}$, 356 that improves the nutrition utilization of pepper, enhances pepper root rot resistance, and 357 increases pepper yield. 
361 The following grant information was disclosed by the authors:

362 The Key Research and Development Project (2017YFD0201600).

363 The National Key Research and Development Program of China (2017YFD0200605).

364 Competing interests

365 The authors declare that they have no conflict of interests.

366 Data Availability

367 The following information was supplied regarding data availability:

368 The NCBI Sequence Read Archive (SRA) database (Accession Number: SRP265722)

369

370

371

372

373

374

375

376

377

378

379

380

381

382

383

384

385

386

387

388

389

390

\section{References}

Aboelnaga HIG, Ahmed NG. 2007. Pathogenicity, toxicity and gibberellic acid content of Fusarium moniliforme causing root rot and damping off of pepper. Plant Pathology Journal 6:318-323 DOI 10.3923/ppj.2007.318.323.

Bak WC. 2011. Characteristics of bed-log of shiitake damaged by Bjerkandera adusta and antagonism between these two fungi [J]. The Korean Journal of Mycology 39(1) DOI 10.4489/KJM.2011.39.1.044.

Beckman CH. 1987. The Nature of Wilt Diseases of Plants. St Paul, USA.

Bhat AK. 2013. Preserving microbial diversity of soil ecosystem: a key to sustainable productivity. International Journal of Current Microbiology and Applied Sciences 2:85101.

Cai GL, Zhao CS, Peng XH, Wu PH, Zhang F, Wang H. 2019. Isolation and identification of pathogenic fungi of pepper root rot and biological agents of Gauze No. 15 in Shiyan. Journal Platform of Central China Normal University 53(2):249-254. (in Chinese)

Cao Y, Chang ZZ, Wang JD, Ma Y, Yang H, Fu GQ. 2014. Potential use of anaerobically digested manure slurry to suppress Phytophthora root rot of chilli pepper. Scientia Horticulturae, 168(26): 124-131 DOI 10.1016/j.scienta.2013.11.004.

Chen XH, Koumoutsi A, Scholz R, Eisenreich A, Schneider K, Heinemeyer I, Morgenstern B, Voss B, Hess WR, Reva O, Junge H, Voigt B, Jungblut PR, Vater J, Süssmuth R, Liesegang H, Strittmater A, Gottschalk G, Borriss R. 2007. Comparative analysis of the complete 
391

392

393

394

395

396

397

398

399

400

401

402

403

404

405

406

407

408

409

410

411

412

413

414

415

416

417

418

419

420

genome sequence of the plant growth-promoting bacterium Bacillus amlolique faciens FZB42. Nature Biotechnology 25:1007-1014 DOI 10.1038/nbt1325.

Coolon JD, Jones KL, Todd TC, Blair JM, Herman MA. 2013. Long-term nitrogen amendment alters the diversity and assemblage of soil bacterial communities in tallgrass prairie. Plos One 8:e67884 DOI 10.1371/journal.pone.0067884.

Ding J, Jiang X, Ma M, Zhou B, Guan D, Zhao B, Zhou J, Cao F, Li L, Li J. 2016. Effect of 35 years inorganic fertilizer and manure amendment on structure of bacterial and archaeal communities in black soil of northeast China. Applied Soil Ecology 105:187-195 DOI 10.1016/j.apsoil.2016.04.010.

Dománski S. 1982. Bjerkandoera adusta on young Quercus rubra and Quercus robur injured by late spring frosts in the upper Silesia industrial district of Poland [J]. Europpean Journal of forest Pathology 12(6):406-413.

Ekea P, Nana WL, Tsouh FPV, Virginie TE, Prasard KS, Kamdem HW, Fekam BF. 2019. Improved nutrient status and Fusarium root rot mitigation with an inoculant of two biocontrol fungi in the common bean (Phaseolus vulgaris L.). Rhizosphere DOI 10.1016/j.rhisph.2019.100172.

Francis I, Holsters M, Vereecke D. 2010. The Gram-positive side of plant-microbe interactions. Environmental Microbiology 12:1-12 DOI 10.1111/j.1462-2920.2009.01989.x.

Fravel, D.R. 2005. Commercialization and implementation of biocontrol. Annual Review of Phytopathology 43:337-359 DOI 10.1146/annurev.phyto.43.032904.092924.

Green SJ, Prakash O, Jasrotia P, Overholt WA, Cardenas E, Hubbard D, Tiedje JM, Watson DB, Schadt CW, Brooks SC, Kostka JE. 2012. Denitrifying bacteria from the genus Rhodanobacter dominate bacterial communities in the highly contaminated subsurface of a nuclear legacy waste site[J]. Applied and Environmental Microbiology 78(4):1039-1047 DOI 10.1128/AEM.06435-11.

Han LJ, Wang ZY, Na L, Wang YH, Feng JT, Zhang X. 2019. Bacillus amyloliquefaciens B1408 suppresses Fusarium wilt in cucumber by regulating the rhizosphere microbial community. Applied Soil Ecology 136:55-66 DOI 10.1016/j.apsoil.2018.12.011.

Hemmc CL, Green SJ, Rishishwar L, Prakash O, Pettenato A, Chakraborty R, Deutschbauer AM, Van Nostrand JD, Wu L, He Z, Jordan IK, Hazen TC, Arkin AP, Kostka JE, Zhou J. 2016. 
421

422

423

424

425

426

427

428

429

430

431

432

433

434

435

436

437

438

439

440

441

442

443

444

445

446

447

448

449

Laternal gene transfer in a heavy metal-contaminated-groundwater microbial community[J]. mBio 7(2): c02234-15. DOI 10.1128/mbio.02234-15.

Hussain S, Siddique T, Saleem M, Arshad M, Khalid A. 2009. Chapter 5 Impact of Pesticides on soil microbial diversity, enzymes, and biochemical reactions. Advances in Agronnomy 102:159-200 DOI 10.1016/S0065-2113(09)01005-0.

Ikeda K. 2010. Role of perithecia as an inoculum source for stem rot type of pepper root rot caused by Fusarium solani f. sp. Piperis (teleomorph: Nectria haematococca f. sp. piperis). Journal of General Plant Pathology 76:241-246 DOI 10.1007/s10327-010-0237-2.

Jaber LR, Alananbeh KM. 2018. Fungal entomopathogens as endophytes reduce several species of Fusarium causing crown and root rot in sweet pepper (Capsicum annuum L.). Biological Control 126:117-126 DOI 10.1016/j.biocontrol.2018.08.007.

Jayaraj J, Radhakrishnan NV, Kannan R, Sakthivel K, Suganya D, Venkatesan S, Velazhahan R. 2010. Development of new formulations of Bacillus subtilis for management of tomato damping-off caused by Pythium aphanidermatum. Biocontrol Science and Technology 15(1): 55-65 DOI 10.1080/09583150400015920.

Kennedy AC, Smith KL. 1995. Soil microbial diversity and the sustainability of agricultural soils. Plant Soil 170:75-86 DOI 10.1007/bf02183056.

Liang B, Yang X, He X, Zhou J. 2011. Effects of 17-year fertilization on soil microbial biomass $\mathrm{C}$ and $\mathrm{N}$ and soluble organic $\mathrm{C}$ and $\mathrm{N}$ in loessial soil during maize growth. Biology and Fertility of Soils 47: 121 -128 DOI 10.1007/s00374-010-0511-7.

Luo Y, Liang J, Zeng G, Chen M, Mo D, Li G, Zhang D. 2018. Seed germination test for toxicity evaluation of compost: its roles, problems and prospects. Waste Manage 71:109-114. DOI 10.1016/j.wasman.2017.09.023.

Ma Y, Chang ZZ, Zhao JT, Zhou MG. 2008. Antifungal activity of Penicillium striatisporum Pst10 and its biocontrol effect on Phytophthora root rot of chilli pepper. Biological Control 44(1): 24-31 DOI 10.1016/j.biocontrol.2007.10.005.

Mehta CM, Palni U, Franke-Whittle IH, Sharma AK. 2014. Compost: its role, mechanism and impact on reducing soil-borne plant diseases. Waste Manage 34:607-622 DOI 10.1016/j.wasman.2013.11.012. 
450 Ohkuma M, Maeda Y, Johjima T, Johjima T, Kudo T. 2001. Lignin degradation and roles of

451

452

453

454

455

456

457

458

459

460

461

462

463

464

465

466

467

468

469

470

471

472

473

474

475

476

477

478

479

white rot fungi: Study on an efficient symbiotic system in fungus-growing termites and its application to bioremediation. Riken Reviews 42: 39-42.

Pérez Hernández A, Serrano Alonso Y, Aguilar Pérez MI, María-Gómez R. 2014. Damping-off and root rot of pepper caused by Fusarium oxysporum in Almería Province, Spain. Plant Disease 98(8):1159-1160 DOI 10.1094/PDIS-02-14-0212-PDN.

Prakash O, Green SJ, Jasrotia P, Overholt WA, Canion A, Watson DB, Brooks SC, Kostka JE. 2012. Rhodanobacter denitrificans sp. nov., isolated from nitrate-rich zones of a contaminated aquifer. International Journal of Systematic and Evolutionary Microbiology 62:2457-2462 DOI 10.1099/ijs.0.035840-0.

Qiao CC, Penton CR, Xiong W, Liu C, Wang RF, Liu ZY, Xu X, Li R, Shen QR. 2019. Reshaping the rhizosphere microbiome by bio-organic amendment to enhance crop yield in a maize-cabbage rotation system. Applied Soil Ecology 142:136-146 DOI 10.1016/j.apsoil.2019.04.014.

Ramirez KS, Lauber CL, Knight R, Bradford MA, Fierer N. 2010. Consistent effects of nitrogen fertilization on soil bacterial communities in contrasting systems. Ecology 91:3463-3470 DOI 10.1890/10-0426.1.

Shen Z, Zhong Z, Wang Y, Wang B, Mei X, Li R, Ruan Y, Shen Q. 2013. Induced soil microbial suppression of banana Fusarium wilt disease using compost and biofertilizers to improve yield and quality. European Journal of Soil Biology 57:1-8 DOI 10.1016/j.ejsobi.2013.03.006.

Singh VS, Maurya BR, Verma JP. 2014. Does a rhizospheric microorganism enhance $\mathrm{K}^{+}$ availability in agricultural soils? Microbiol Research 169:337-347 DOI 10.1016/j.micres.2013.09.003.

Sun RB, Zhang XX, Guo XS, Wang DZ, Chu HY. 2015. Bacterial diversity in soils subjected to long-term chemical fertilization can be more stably maintained with the addition of livestock manure than wheat straw. Soil Biology \& Biochemistry 88:9-18 DOI 10.1016/j.soilbio.2015.05.007.

Tao CY, Li R, Xiong W, Shen ZZ, Liu SS, Wang BB, Ruan YZ, Geisen S, Shen, QR, Kowalchuk GA. 2020. Bio-organic fertilizers stimulate indigenous soil Pseudomonas 
480 populations to enhance plant disease suppression. Microbiome 8(1): 137 DOI $481 \quad 10.1186 /$ s40168-020-00892-Z.

482 Wang H, Yu DZ, Guo J. 2015. Identification and antibacterial activity of Bjerkandera sp. No.15. 483 Green prevention and control of plant diseases and insect pests, and quality and safety of 484 agricultural products. Proceedings of the 2015 Academic Conference of the Chinese Society 485 of Plant Protection. Changchun, China 590. (in Chinese)

486 Wang H. 2018. Bjerkandera sp. Gao's No. 15 and its preparation for preventing and curing 487 vegetable root diseases. CHN. Patent ZL 20151 0564715.4. 2018-01-02.

488 Wang H., Wang HY, Liu CP, Zhang Y. Zhang XJ, Liu YM. 2020. A fermentation material and 489 its preparation method used for sprout cultivation substrate of solanaceous vegetables. 490 Australia, Patent number: 2020101644.

491 Zhou J, Guan D, Zhou B, Zhao B, Ma M, Qin J, Jiang X, Chen S, Cao F, Shen D. 2015. 492 Influence of 34-years of fertilization on bacterial communities in an intensively cultivated 493 black soil in northeast China. Soil Biology \& Biochemistry 90:42-51 DOI $494 \quad$ 10.1016/j.soilbio.2015.07.005. 


\section{Figure 1}

Comparative analysis of OTUs at genus level in each community.

Comparative analysis of OTUs at genus level in each community. $A$ and $C$ are fungi, and $B$ and D bacteria. A and B: Sample hierarchical clustering analysis based on OTU level with distance algorithm based on bray_curtis. $C$ and D: SampleNMDS analysis based on the genus level. $\mathrm{G}=$ biological agent treatment, $\mathrm{C}=$ control condition. 

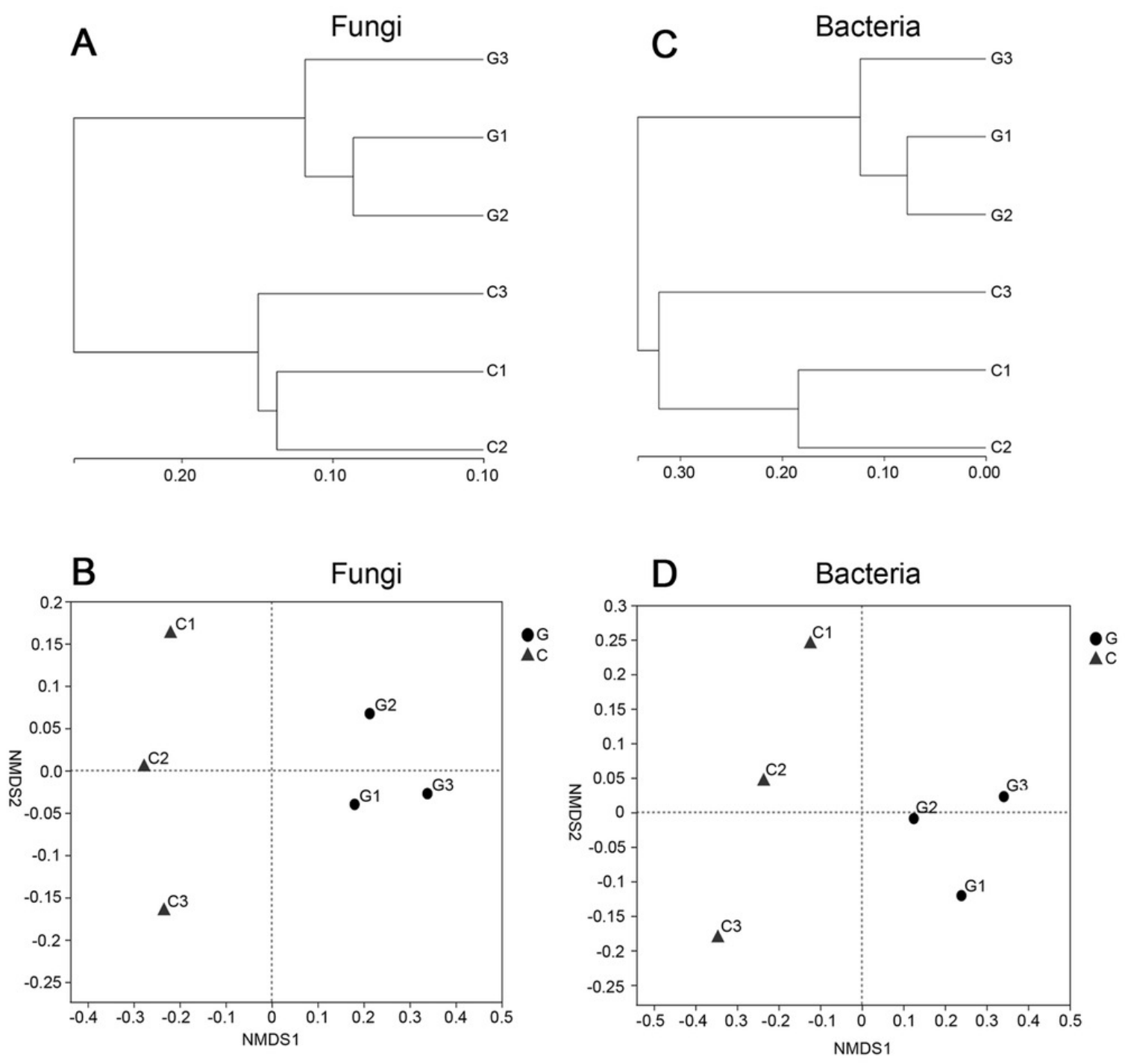

Figure 1 
Figure 2

Heatmap analysis of genus horizontal community.

Heatmap analysis of genus horizontal community. Figure $A$ is for fungus, and Figure $B$ is for bacterial. Only two-fifths of the fungal genera had a richness greater than 1 , and the community structure was more complicated. $\mathrm{G}=$ biological agent treatment, $\mathrm{C}=$ control condition. 
A

Fungi

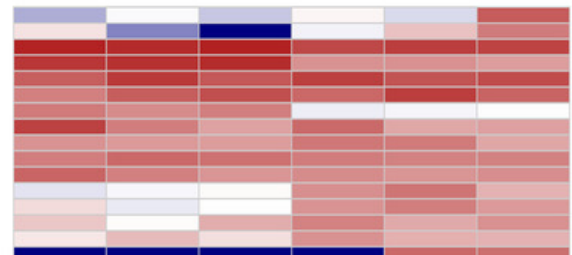

unclassified c_Sordariomycetes unclassified_o_Agaricales

Phialemonium

unclassified_o Eurotiales Pseudaliescheria norank_o-Eurotiales norank - Ascobolaceae norank_ _ Ascomycota norank o Tremellales nclassifiè _ $k$ Fungi unclassified f-Nectriaceae rank $P$-Glomeromycot Fusarium norank p Ascomycota, unclassified-o-Hypocreales

unclassified f norank o Pseudoperkinsidae Acrospermum

Monosiga

norank_o-Pezizales

norank $k$ - Alveolata

unclassifiéd K K Amoebozo

Cochliobōilus

unclassified p_Basidiomycota norank O-Sponidiobolales unclassified d Eukaryota 作 Eocronartium
Arthrobotrys

norank_p_Freshwater_Opisthokont

Archaeorhizomyces

Cladophialophora
unclassified o_Cantharellales

unclassified o C Cantharellales
norank__Basidiomycota norank p-Basidiomycota
unclassified c A Agaricomycetes
norank $p$ Chytridiomycota Pseudoplatyophyra

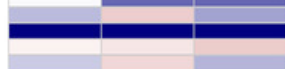

G3

G1

G2

C3

C1

C2

B

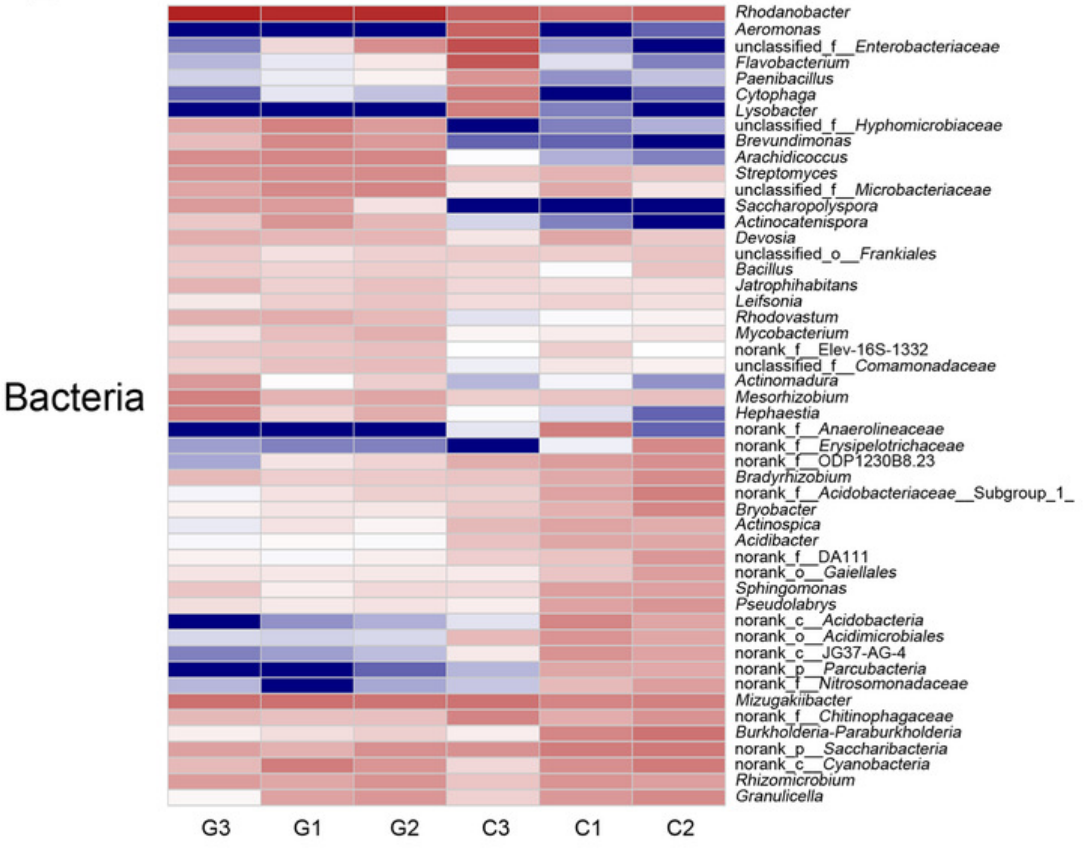

Enterobacteriace ycobacterium 105 esorhizobium norank -Erysipelotrichacea

norank f Acidobacteriaceae Subgroup_1 Actinospica norank f -DA111

rank c Acidobacteria

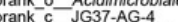
rank orank f Chitinophagaceae Granulicella

Figure 2 


\section{Figure 3}

Venn analysis based on the genus level.

Venn analysis based on the genus level. For the fungal population, there were 39 genera in the two treatments and 22 endemic genera in control, and there was a special Pezizales in the $\mathrm{G}$ treatment. For the bacterial population, there were 245 genera in total in the two treatments, 120 endemic genera in the control condition, and only 47 endemic genera in the $\mathrm{G}$ treatment. $\mathrm{G}=$ biological agent treatment, $\mathrm{C}=$ control condition. 

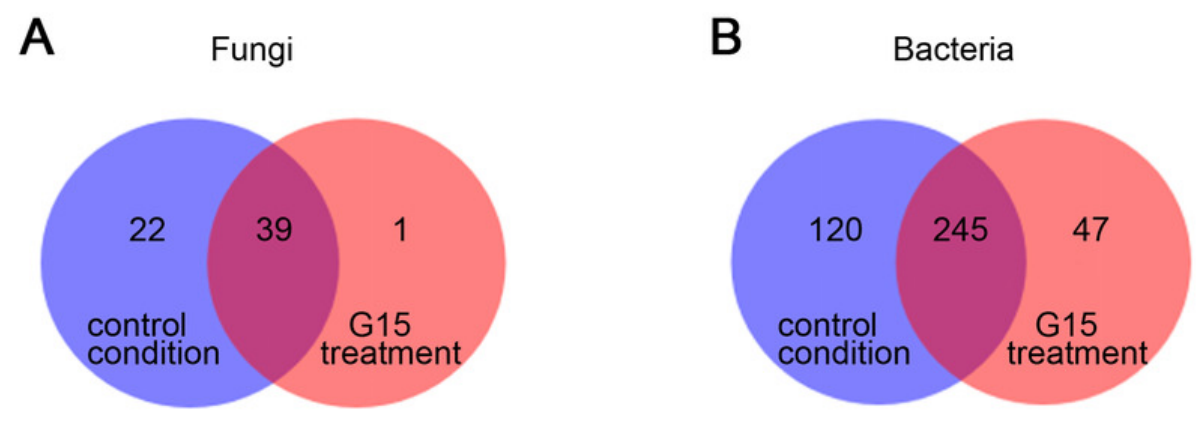

Figure 3 


\section{Figure 4}

Analysis of microbial community composition at the genus or species level.

Analysis of microbial community composition at the genus or species level. Fungal diversity analysis found that the proportion of Phialemonium in the G15 treatment group was significantly higher than of the control group, while the proportion of Fusarium - that is responsible for pepper root rot - was significantly lower than that of the control group. Bacterial diversity analysis found that the proportion of Rhodanobacter in the G15 treatment group was much higher than in the control group. $\mathrm{G}=$ biological agent treatment, $\mathrm{C}=$ control condition. 
A

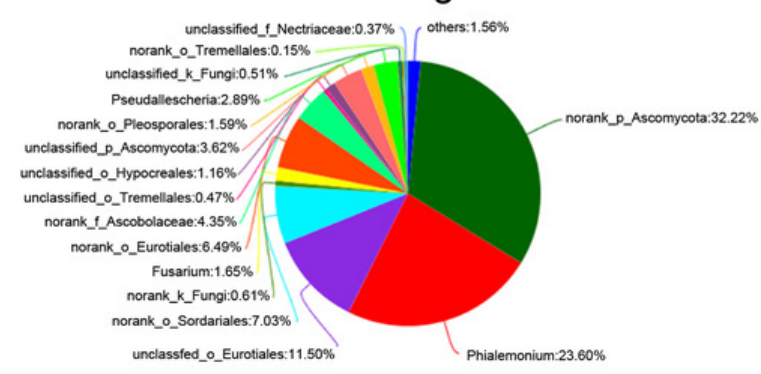

B

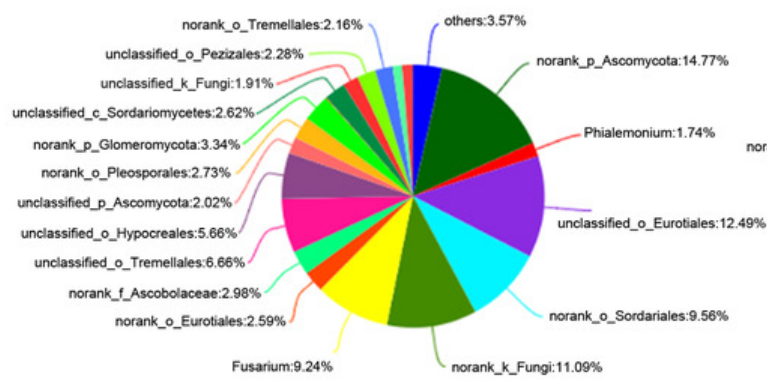

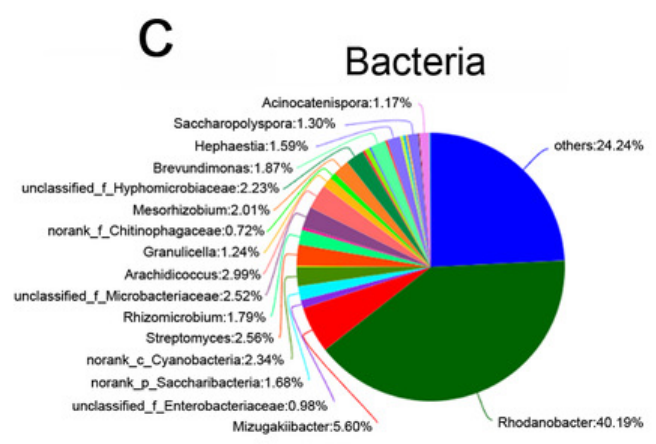

D

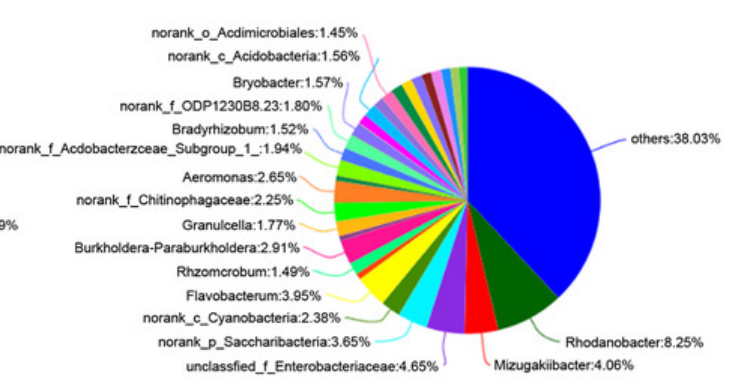

Figure 4 


\section{Table 1 (on next page)}

Pepper biological characteristics, disease indices, and control effect.

Pepper biological characteristics, disease indices, and control effect. 
1 Table 1. Pepper biological characteristics, disease indices, and control effect.

\begin{tabular}{|c|c|c|c|c|c|c|c|c|c|c|c|}
\hline \multirow[b]{2}{*}{$\begin{array}{l}\text { Treatm } \\
\text { ents }\end{array}$} & \multirow[b]{2}{*}{$\begin{array}{l}\text { Plant Height } \\
(\mathrm{cm})\end{array}$} & \multirow[b]{2}{*}{$\begin{array}{l}\text { Root length } \\
(\mathrm{cm})\end{array}$} & \multirow[b]{2}{*}{$\begin{array}{l}\text { Root fresh } \\
\text { weight (g) }\end{array}$} & \multirow[b]{2}{*}{$\begin{array}{l}\text { Root dry } \\
\text { weight }(\mathrm{g})\end{array}$} & \multicolumn{5}{|l|}{ Pepper yield } & \multirow[b]{2}{*}{$\begin{array}{l}\text { Disease } \\
\text { index }\end{array}$} & \multirow{2}{*}{$\begin{array}{l}\text { Control } \\
\text { effect } \\
(\%)\end{array}$} \\
\hline & & & & & first & $\begin{array}{l}\text { second } \\
(\mathrm{kg})\end{array}$ & $\begin{array}{l}\text { third pick } \\
(\mathrm{kg})\end{array}$ & $\begin{array}{l}\text { fourth pick } \\
(\mathrm{kg})\end{array}$ & $\begin{array}{l}\text { fifth pick } \\
(\mathrm{kg})\end{array}$ & & \\
\hline $\mathrm{C} 1$ & $45.72 \pm 3.94$ & $16.73 \pm 2.40$ & $12.59 \pm 2.48$ & $2.48 \pm 0.32$ & $513 \pm 15.47$ & $457 \pm 7.70$ & $268 \pm 7.23$ & & & $16.87 \pm 2.68$ & \\
\hline $\mathrm{C} 2$ & $47.64 \pm 4.10$ & $18.35 \pm 2.33$ & $13.57 \pm 1.93$ & $2.75 \pm 0.25$ & $527 \pm 9.46$ & $468 \pm 5.98$ & $273 \pm 9.04$ & & & $17.86 \pm 1.82$ & - \\
\hline C3 & $43.93 \pm 5.16$ & $14.78 \pm 2.61$ & $9.05 \pm 1.95$ & $2.33 \pm 0.23$ & $508 \pm 9.86$ & $449 \pm 6.26$ & $261 \pm 8.82$ & . & - & $15.64 \pm 1.23$ & \\
\hline G1 & $61.83 \pm 1.45$ & $23.45 \pm 3.51$ & $18.93 \pm 3.98$ & $4.35 \pm 0.27$ & $586 \pm 17.17$ & $513 \pm 9.63$ & $458 \pm 8.85$ & $415 \pm 5.66$ & $287 \pm 8.92$ & $2.35 \pm 0.29$ & $76.53 \pm 1.58$ \\
\hline $\mathrm{G} 2$ & $63.75 \pm 3.63$ & $25.89 \pm 3.30$ & $20.37 \pm 2.68$ & $4.67 \pm 0.35$ & $597 \pm 15.17$ & $526 \pm 8.08$ & $467 \pm 8.26$ & $423 \pm 6.80$ & $291 \pm 5.85$ & $3.17 \pm 0.24$ & $77.69 \pm 2.21$ \\
\hline G3 & $65.31 \pm 3.70$ & $27.35 \pm 3.62$ & $24.58 \pm 2.66$ & $4.93 \pm 0.28$ & $618 \pm 6.73$ & $531 \pm 9.91$ & $477 \pm 9.70$ & $431 \pm 6.96$ & $293 \pm 5.02$ & $4.13 \pm 0.38$ & $78.32 \pm 1.95$ \\
\hline
\end{tabular}

$\mathrm{G}=$ biological agent treatment, $\mathrm{C}=$ control condition. 


\section{Table 2 (on next page)}

Selected physicochemical characteristics for soils according to biological agent treatment and control condition.

Selected physicochemical characteristics for soils according to biological agent treatment and control condition. 
1 Table 2. Selected physicochemical characteristics for soils according to biological agent 2 treatment and control condition.

\begin{tabular}{|l|l|l|l|l|l|l|}
\hline Items & $\mathrm{pH}$ & TOC mg/g & $\mathrm{NH}_{4}{ }^{+}-\mathrm{N} \mathrm{mg} / \mathrm{kg}$ & \multicolumn{1}{l}{$\mathrm{N}$} & & \\
$\mathrm{mg} / \mathrm{kg}$ & & Total P g/kg & Total K g/kg \\
\hline G1 & $7.56 \pm 0.04$ & $39.6 \pm 2.9$ & $39.24 \pm 5.9$ & $763.4 \pm 15.9$ & $4.91 \pm 0.12$ & $54.21 \pm 2.9$ \\
\hline G2 & $7.48 \pm 0.07$ & $36.4 \pm 3.8$ & $28.38 \pm 5.2$ & $812.6 \pm 25.2$ & $4.63 \pm 0.21$ & $56.23 \pm 3.9$ \\
\hline G3 & $7.28 \pm 0.09$ & $38.2 \pm 4.4$ & $39.46 \pm 4.4$ & $694.2 \pm 26.4$ & $4.32 \pm 0.23$ & $52.16 \pm 4.7$ \\
\hline C1 & $5.68 \pm 0.08$ & $10.2 \pm 2.4$ & $116.26 \pm 8.6$ & $685.6 \pm 28.6$ & $4.36 \pm 0.20$ & $47.23 \pm 4.6$ \\
\hline C2 & $5.24 \pm 0.11$ & $9.6 \pm 2.1$ & $136.64 \pm 5.2$ & $786.4 \pm 25.2$ & $4.96 \pm 0.24$ & $45.36 \pm 5.2$ \\
\hline C3 & $5.62 \pm 0.08$ & $11.6 \pm 2.3$ & $128.28 \pm 6.4$ & $826.5 \pm 16.4$ & $4.82 \pm 0.21$ & $45.98 \pm 4.4$ \\
\hline
\end{tabular}

$3 \mathrm{G}=$ biological agent treatment, $\mathrm{C}=$ Control condition. 


\section{Table 3 (on next page)}

Alpha diversity index analysis reflecting community richness, community evenness, community diversity, and community coverage between the G15-treatment and control conditions.

Alpha diversity index analysis reflecting community richness, community evenness, community diversity, and community coverage between the G15-treatment and control conditions. 
1 Table 3. Alpha diversity index analysis reflecting community richness, community evenness, 2 community diversity, and community coverage between the G15-treatment and control 3 conditions.

\begin{tabular}{|l|l|l|l|l|l|l|}
\hline & \multicolumn{3}{|c|}{ Fungi } & \multicolumn{3}{c|}{ Bacteria } \\
\hline Estimators & C-Mean & G-Mean & P-value & C-Mean & G-Mean & P-value \\
\hline shannon & $2.8632 \pm 0.1075$ & $2.0811 \pm 0.1065$ & 0.0009 & $4.1546 \pm 0.5282$ & $3.13 \pm 0.28$ & 0.0412 \\
\hline simpson & $0.0831 \pm 0.0099$ & $0.1951 \pm 0.0208$ & 0.0011 & $0.0346 \pm 0.0218$ & $0.1748 \pm 0.0484$ & 0.0102 \\
\hline sobs & $83 \pm 6.9282$ & $53.333 \pm 1.1547$ & 0.0019 & $281 \pm 43.589$ & $239 \pm 7.8102$ & 0.1758 \\
\hline ace & $89.725 \pm 6.9945$ & $62.891 \pm 9.1255$ & 0.0156 & $300.34 \pm 38.639$ & $258.17 \pm 6.1596$ & 0.1353 \\
\hline chao & $87.958 \pm 7.8902$ & $59.917 \pm 6.8795$ & 0.0097 & $302.99 \pm 45.157$ & $264.31 \pm 11.553$ & 0.224 \\
\hline coverage & $0.9997 \pm 0.0001$ & $0.9997 \pm 0.0001$ & 0.588 & $0.999 \pm 0.0002$ & $0.999 \pm 0.0002$ & 1 \\
\hline
\end{tabular}

$4 \mathrm{G}=$ biological agent treatment, $\mathrm{C}=$ control condition. 